\title{
Remembering words not presented in lists: Can we avoid creating false memories?
}

\author{
DAVID A. GALLO, MEREDITH J. ROBERTS, and JOHN G. SEAMON \\ Wesleyan University, Middletown, Connecticut
}

\begin{abstract}
Can subjects avoid creating false memories as outlined in Roediger and McDermott's (1995) false recognition paradigm if they are forewarned about this memory illusion? We presented subjects with semantically related word lists, followed by a recognition test. The test was composed of studied words, semantically related nonstudied words (critical lures), and unrelated nonstudied words. One group of subjects was uninformed about the false recognition effect, a second group was urged to minimize all false alarms, and a third group was forewarned about falsely recognizing critical lures. Compared with the uninformed and cautious subjects, the forewarned subjects reduced their false alarm rate for critical lures, and they made remember and know judgments equally often for recognized studied words and critical lures. But forewarning did not eliminate the false recognition effect, as these subjects and those in the other groups made numerous false recognitions in this task.
\end{abstract}

In a special issue of the Journal of Memory and Language devoted to research on memory illusions, Roediger (1996) provided a historical overview of errors in perception and memory. He defined a memory illusion as an instance in which a person's report of a past event seriously deviates from the actual event. One striking example offered as evidence of a memory illusion was Deese's (1959) finding of false recall in a list-learning paradigm. Deese presented subjects with lists of semantic associates to nonpresented critical words. For example, for the critical word needle, the presented list consisted of thread, pin, eye, sewing, sharp, point, pricked, thimble, haystack, pain, hurt, and injection. When the subjects were given a free recall test after each list's presentation, the nonpresented critical word was often erroneously recalled more frequently than nonpresented but unrelated words. This procedure induced subjects to recall specific words that were never presented in the lists. Beginning with Roediger and McDermott (1995), there has been a revival of interest in this paradigm for studying this false memory effect (e.g., McDermott, 1996; Payne, Elie, Blackwell, \& Neuschatz, 1996; Read, 1996; Schacter, Verfaellie, \& Pradere, 1996).

Roediger and McDermott (1995) reported two experiments that replicated and extended Deese's (1959) result. In their first experiment, the subjects were read six of Deese's lists that elicited the highest frequency of false recall. After each list was presented, the subjects were given a free recall test, followed by a recognition test after all of the lists were recalled. The recognition test

Appreciation is expressed to Chun Luo for helpful comments on an earlier draft of this paper. This research was supported by a Wesleyan Grant in Support of Scholarship made to J.G.S. Correspondence should be addressed to J. G. Seamon, Department of Psychology, Wesleyan University, Middletown, CT 06459-0408 (e-mail: jseamon@, wesleyan.edu). was composed of studied words, nonstudied critical words (hereafter referred to as "critical lures"), and nonstudied unrelated words. Roediger and McDermott found that the critical lures were falsely recalled and recognized more frequently than were other nonstudied words.

In their second experiment, Roediger and McDermott (1995) modified their procedure. Half of the subjects received a free recall test after each study list presentation, and half performed unrelated math problems instead. On the subsequent recognition test, the researchers made use of Tulving's (1985) remember versus know judgment task. For any recognized word, the subjects had to indicate whether they specifically remembered the word's occurrence at study (a remember judgment) or they merely knew the word had been presented in the absence of any specific recollection (a know judgment). Roediger and $\mathrm{McDermott}$ found that the study and recall condition led to more false recognitions of critical lures than did the study and math condition. However, the subjects in both conditions produced false alarms to the critical lures at rates that were comparable to the corresponding hit rates for studied words. Moreover, the results showed that recognized critical lures were often characterized as remembered in the remember versus know judgment task, especially in the study and recall condition. These observations led Roediger and McDermott to describe the false recognition effect as a "powerful illusion of memory" (p. 803). This illusion is all the more surprising, they said, because it was observed under intentional learning conditions, with short retention intervals, in a listlearning laboratory procedure that normally produces few errors, and with professional memorizers (college students) as subjects.

The primary purpose of the present research was to determine whether subjects could avoid creating false memories in Roediger and McDermott's (1995) false recognition paradigm if they were forewarned about this memory 
illusion. To our knowledge, no one has specifically determined whether this false memory effect can be diminished or eliminated by the subjects' knowledge, but prior research has asked whether different experimental conditions can influence this effect. For example, McDermott (1996, Experiment 2) gave subjects multiple study and recall tests with the same word lists presented in either a blocked or a random manner. She found that random presentation produced less false recall than blocked presentation, but both forms of presentation still yielded false recalls after multiple study-test trials or a final recall test given $24 \mathrm{~h}$ later. Payne et al. (1996) observed a similar effect, showing that recognition of critical lures did not decrease over a $24-\mathrm{h}$ retention interval. Finally, Read (1996) manipulated encoding instructions by having subjects memorize word order or engage in elaborative or maintenance rehearsal during list presentation. He found that all three encoding conditions yielded high levels of false recall for critical words, but the false recalls were lowest for the subjects who focused on word order. These studies indicate that the false memory effect persists through multiple study and test trials (McDermott, 1996), a 24-h delay between study and test (McDermott, 1996; Payne et al., 1996), and elaborative or maintenance rehearsal during encoding (Read, 1996). But false memory for critical words is diminished when the words are randomized over lists (McDermott, 1996) or the subjects attempt to memorize word order at study (Read, 1996).

Following those studies, the present research sought to determine whether the false recognition of critical lures could be attenuated or eliminated by the use of forewarning instructions. Curiously, we found no published research on the effects of foreknowledge on perceptual or memory illusions. For perceptual illusions, such research may have been unnecessary; Gregory (1987) noted that these illusions occur even when people know that they are perceiving an illusion. For example, we may know that the lines in the Müller-Lyer illusion are equal in length, yet one line still appears to be longer than the other. Perceptual illusions fool us because perceptual processes work extremely rapidly and do not take everything that we know into account in the process of forming a percept (Gregory, 1987). Memory illusions also fool us, but they do so over a more extended time frame that includes study and test conditions. Memory illusions may thus provide greater opportunity than perceptual illusions to be influenced by the subject's knowledge. To the extent that foreknowledge can be used during encoding or retrieval to devise compensatory cognitive strategies, an illusion may be diminished or eliminated.

The only statements we found about the effects of foreknowledge on false memory are located in two places in Roediger and McDermott's (1995) research. One statement suggests that forewarning might be effective in minimizing the false recognition of critical lures, whereas the other statement suggests little effect of forewarning. For example, the authors noted that they dropped the only subject from their analysis who had no false recalls of the critical words because at the end of Experiment 2, when the subjects were asked if they "knew what the experiment was about," this subject reported that "she noticed that the lists seemed designed to make her think of a nonpresented word" (p. 808). This subject may have adopted a strategy that permitted her to overcome the memory illusion. However, Roediger and McDermott also reported that "informal demonstration experiments with groups of sophisticated subjects, such as wily graduate students who knew we were trying to induce false memories" still produced a strong false memory effect (p. 812). To the extent that these subjects were fully informed about this memory illusion before study, this observation suggests that forewarning will have a minimal effect on the false recognition of critical words.

The present research tested these foreknowledge alternatives systematically by comparing groups of subjects with different instructional sets in a modified version of the Roediger and McDermott (1996, Experiment 2) paradigm. To the extent that this false memory effect is a memory illusion that functions like a perceptual illusion, foreknowledge of the effect may have little or no effect on the recognition of critical lures. But if this memory illusion differs from perceptual illusions in that it allows greater opportunity for performance to be influenced by encoding or retrieval strategies, foreknowledge of the illusion should attenuate the effect to the extent that people can devise effective compensatory strategies. We presented subjects with blocked lists of semantically related words for study, followed by a recognition test after all lists were presented. One group of subjects was uninformed about the false recognition effect, a second group was urged to be cautious at the time of the recognition test to minimize all false alarms, and a third group was forewarned of the specific illusion by a demonstration and instructions before study. On the basis of Roediger and McDermott's findings, we hypothesized that the subjects in the uninformed condition would produce a strong false recognition effect. Subjects in the cautious and forewarned groups provide novel test conditions, and, compared with the uninformed condition, they should produce either a comparable or a diminished effect.

\section{METHOD}

\section{Subjects}

The subjects were 48 Wesleyan University undergraduates who served as paid volunteers. None had participated in any related memory research.

\section{Materials}

We used 16 of Roediger and McDermott's 24 word lists for study and test words (see their appendix). Each list was composed of 15 associates to a nonpresented critical word (i.e., a critical lure). Within a list, the order of the words was constant and the strongest associates to the critical lure normally occurred first. For example, the list associated with the critical lure sleep consisted of the following words: bed, rest, awake, tired, dream, wake, snooze, blanket, doze, slumber. snore, nap, peace, yawn, and drowsy. For counterbalancing purposes, the 16 lists were divided into two sets of 8 lists, labeled A and B. Half 
of the subjects in each condition received Set A for study and half re ceived Set B. The set not used during study provided distractors for the recognition test.

\section{Procedure}

During study, the subjects were presented with an auditory tape containing eight lists of 15 words presented in blocked fashion. The words were spoken by a male voice at a rate of $1.5 \mathrm{sec}$ per word, and a tone separated each list. The subjects, who were tested in groups of up to 6 , were told to remember the words for a recognition memory test that would follow.

After all 120 study words were heard, the subjects were given a visual recognition memory test consisting of 64 words. Following Roediger and McDermott's (1995) test procedure, this test contained three items from each studied list (Serial Positions 1, 8, and 10), the nonpresented critical lure from each studied list, three items from each nonstudied list (Serial Positions 1, 8, and 10), and the critical lure from each nonstudied list, all listed in a random order. Each word was accompanied by a plus ( + ) and a minus ( -$)$ sign and the letters $R$ and $K$ (for remember and know).

The subjects were instructed to examine the words in sequential order at a self-paced rate and to make a decision for each word on the list. They were told to circle the plus sign for any word that they recognized from the study tape or the minus sign for any word they failed to recognize. In addition, following Tulving (1985), the subjects were instructed to make a remember or know judgment for each recognized word by circling $R$ or $K$ on their answer sheets. The subjects were told to circle $R$ if they had a conscious recollection of the word from the study lists, such as the way the word was presented or what they were thinking about at the time, or $K$ if they were sure the word was presented, but they could not recollect its actual uccurrence or any related details. These instructions for remember and know judgments were similar to those used by Rajaram (1993) and Roediger and McDermott (1995). After the recognition test, the subjects completed a questionnaire that assessed their awareness of the organization of the word lists at study and asked for a description of any strategies that were used to reduce false recognitions.

The variable of primary interest in this experiment was the effect of foreknowledge on the false memory effect. Accordingly, three groups of 16 subjects received different instructions at study or test. In the uninformed condition, the subjects were not told about the false recognition effect. Instead, they were given standard instructions to try to remember as many words as possible for a subsequent recognition test. This condition is similar to the general procedure used by Roediger and McDermott (1995, Experiment 2).

In the cautious condition, the subjects were also uninformed about the false recognition effect during study, but they were asked to be careful on the recognition test in order to minimize their false recognitions to all words. This condition was designed to determine whether merely asking subjects to be cautious was sufficient to minimize the false recognition effect for critical lures. Unlike the subjects in the uninformed condition, who received no information about the words used in the recognition test, these subjects were told that some words on the test were similar to words heard at study but were not actually presented. No other information was provided.

In the forewarned condition, the subjects were provided with detailed information and examples of the false recognition effect prior to the presentation of the study lists. Because the subjects were specifically told that the study lists were designed to try to make them falsely recognize related but nonpresented words, this condition allowed subjects the chance to devise strategies to reduce or eliminate the false recognition effect. As part of the forewarning procedure, the subjects participated in a false recognition demonstration before instructions for the actual experiment were given. The subjects were read a sample list of words and told that they would be given a practice recognition test to familiarize themselves with the procedure. The list was obtained from Roediger and McDermott (1995) and not used elsewhere in this experiment. Following the presentation of the sample list, subjects were given an eight-word recognition test, constructed in the same manner as our actual test. Three of the words were from the sample list (Serial Positions 1, 8, and 10), one word was the nonpresented critical lure, and four words were unrelated distractors taken from another Roediger and McDermott list not used again in this experiment. After the subjects completed the sample recognition test, the critical lure was identified, and the false recognition effect was described.

These subjects were further informed that prior research had demonstrated that presenting lists of words that were semantically associated to nonpresented words led to high levels of false recognition of the critical lures. This discussion was followed by a reading of another sample list of 15 related words, along with its critical lure from another Roediger and McDermott list that was not used again in this experiment. The subjects were told that the lists that they would hear at study were constructed in the same fashion as the sample lists. Their task was to minimize the false recognition of critical lures without sacrificing their recognition of words presented at study. Care was taken to ensure that the subjects understood the manner in which the study lists were constructed, the nature of the false recognition effect, and the goal of minimizing the false recognition of critical lures. Prior to the recognition test, the subjects were reminded of their task. Together, these procedures provide a strong test of any possible effect of forewarning.

\section{RESULTS}

The primary data consisted of the responses to the recognition test for subjects in the uninformed, cautious, and forewarned conditions and the remember versus know judgments for all of the words that were recognized. These results are shown in Table 1 for each condition and response measure.

Table 1 indicates that the hit rate for studied words varied across groups, and this observation was supported by the results of an analysis of variance $[F(2,42)=4.62$, $\left.M S_{\mathrm{e}}=.02, p<.02\right]$. The hit rate for the uninformed group (.76) was greater than that for the cautious group (.65) $[t(30)=2.33, S E M=.05, p<.05]$ and the fore-

Table 1

Mean Recognition for Studied and Nonstudied Words and Related and Unrelated Critical Lures

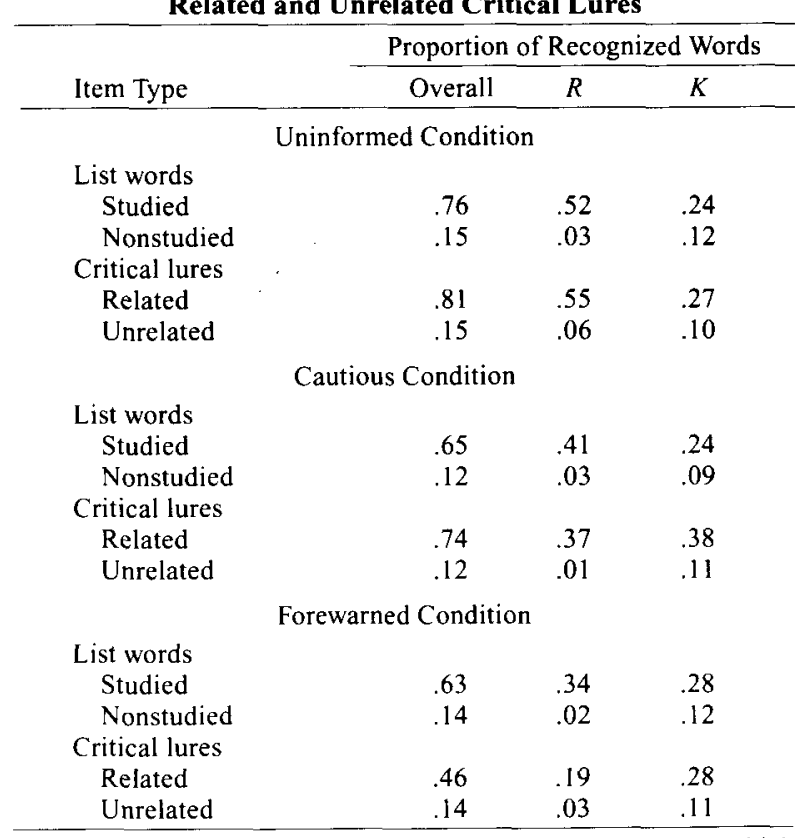

Note- $R$, remember judgment; $K$, know judgment. Instances in which remember and know proportions do not sum to the overall proportion reflect rounding to two decimal places. 
warned group $(.63)[t(30)=3.01, S E M=.04, p<.01]$, whereas the hit rates for the cautious and forewarned groups did not vary $(t<1)$. There was also an effect of groups on the false recognition rate for critical lures $\left[F(2,42)=11.05, M S_{\mathrm{e}}=.05, p<.0001\right]$, as the rate for the forewarned group (.46) was less than that for the uninformed group (.81) $[t(30)=4.84, S E M=.07, p<$ $.001]$ and the cautious group (.74) $[t(30)=3.36, S E M=$ $.08, p<.01]$. The false alarm rates for critical lures for the uninformed and cautious groups did not vary $(t<1)$, and there was no overall effect of groups on the false alarm rates for nonstudied words or unrelated critical lures (both $F \mathrm{~s}<1$ ).

In addition to producing the highest hit rate, the uninformed group also produced a strong false memory effect by falsely recognizing the nonpresented critical lures $(.81)$ at least as frequently as the studied words (.76) $[t(15)=1.25, S E M=.04, p>.10]$. On the remember versus know judgment task, these subjects selected remember responses more frequently than know responses for recognized studied words $[t(15)=4.43, S E M=.06$, $p<.001]$ and falsely recognized critical lures $[t(15)=$ $2.40, S E M=.11, p<.05]$. Their false alarm rates for nonstudied words and unrelated critical lures were the same (.15), and most of these false alarms were judged as know responses. These results closely replicate Roediger and McDermott's (1995, Experiment 2, Table 2) results and indicate that when subjects are uninformed about this memory illusion, they cannot differentiate list items from semantically related but nonpresented items.

The finding that subjects in the cautious group had a significantly lower overall hit rate and nonsignificantly lower false alarm rates than did subjects in the uninformed group suggests that the instructions to be cautious influenced recognition performance. But even though these subjects exercised caution, they still demonstrated a false memory effect by recognizing critical lures (.74) at least as often as studied words $(.65)[t(15)=$ $1.8, S E M=.05, p>.05]$. However, these subjects, who selected remember responses over know responses for

Table 2

Hits for Studied Words and False Alarms for Critical Lures According to Self-Reported Strategies

\begin{tabular}{|c|c|c|c|c|}
\hline \multirow[b]{2}{*}{ Condition } & \multicolumn{4}{|c|}{ Self-Reported Strategy } \\
\hline & $\begin{array}{c}\text { None } \\
\text { Indicated }\end{array}$ & $\begin{array}{c}\text { Maintenance } \\
\text { Rehearsal }\end{array}$ & $\begin{array}{c}\text { Elaborative } \\
\text { Rehearsal }\end{array}$ & $\begin{array}{c}\text { Determine } \\
\text { Critical Lures } \\
\end{array}$ \\
\hline \multicolumn{5}{|l|}{ Uninformed } \\
\hline$N$ & 3 & 2 & 8 & 3 \\
\hline Hits & .71 & .71 & .81 & .74 \\
\hline FAs & .83 & .81 & .89 & .58 \\
\hline \multicolumn{5}{|l|}{ Cautious } \\
\hline$N$ & 4 & 1 & 9 & 2 \\
\hline Hits & .56 & .83 & .66 & .71 \\
\hline FAs & .59 & .88 & .82 & .63 \\
\hline \multicolumn{5}{|l|}{ Forewarned } \\
\hline$N$ & 4 & 2 & 3 & 7 \\
\hline Hits & .49 & .65 & .65 & .68 \\
\hline FAs & .28 & .69 & .58 & .45 \\
\hline
\end{tabular}

Note- $-N$, number of subjects; hits and false alarms (FAs) are proportions. recognized studied words $[t(15)=2.67, S E M=.06$, $p<.05$ ], did not differentiate these responses for falsely recognized critical lures $[t<-1]$. Their false alarm rates were the same for nonstudied words and unrelated critical lures (.12), and most of these false alarms were judged as know responses. These results indicate that instructing subjects to be cautious can lower the hit rate for studied words and reduce the likelihood that falsely recognized critical lures will be judged as remembered from the prior lists. But such instructions do not diminish the false recognition effect. Merely asking people to be cautious about their false alarms has little effect on this memory illusion.

Most important, the subjects in the forewarned group had a lower overall hit rate and a lower false alarm rate for critical lures than did subjects in the uninformed group. At the same time, they had a comparable hit rate and a lower critical lure false alarm rate than did subjects in the cautious group. These subjects still made more false recognitions of critical lures (.46) than of unrelated critical lures (.14) $[t(15)=5.39, S E M=.06, p<.001]$, demonstrating the persistence of the false memory effect. But their lower rate of false recognition of critical lures, relative to that rate for either the uninformed $(.81)$ or the cautious (.74) group, and their lower rate of false recognition of critical lures relative to their hit rate $[t(15)$ $=3.2, S E M=.05, p<.01]$ indicates that forewarning instructions diminished the false recognition effect. Moreover, unlike the uninformed subjects, these subjects did not differentiate between remember and know judgments for either recognized studied words $[t(15)=1.0, S E M=$ $.05, p>.10]$ or critical lures $[t(15)=-1.3, S E M=.08$, $p>.10]$. As in the previous conditions, the false alarm rates for nonstudied words and unrelated critical lures were the same (.14), with the majority of these false alarms judged as know responses. These results demonstrate that forewarning instructions can reduce the magnitude of the false recognition effect by reducing the proportion of falsely recognized critical lures and the proportion of those false recognitions judged to be remembered from study.

\section{The Postexperiment Questionnaire}

An open-ended questionnaire was given to all subjects at the end of the experiment. It was designed to provide information about subject awareness of study list organization and the types of strategies that were used to maximize performance on the recognition test. For subjects in the cautious group, we were interested in determining how they might reduce their false alarms to all nonstudied words, whereas for subjects in the forewarned group, we wanted to know how they attempted to minimize their susceptibility to recognizing critical lures. Each subject's written statement was sorted into one of four categories on the basis of the specific strategy that was described. Those categories consisted of the following: no strategy indicated (these subjects made no report of any strategy), maintenance rehearsal (these subjects focused on the sound of each list word or repeated them silently during 
study), elaborative rehearsal (these subjects focused on list themes by linking study words by semantic associations or forming visual images of the words), and determine critical lures (in addition to focusing on each list's theme, these subjects tried to determine and remember each list's critical lure). Table 2 shows the number of subjects in each category from each group, along with the corresponding average hit rate for studied words and false alarm rate for critical lures. False alarm rates for nonstudied words and unrelated critical lures were not included because these rates were low in each condition and did not differ across groups.

The results shown in Table 2 indicate that subjects in the uninformed and cautious groups produced a similar pattern of results. These subjects were more apt to report that they used elaborative rehearsal as their primary means of remembering list words (17 out of 32, or .53) than either maintenance rehearsal ( 3 out of 32 , or .09 ) or a strategy aimed at determining the critical lures ( 5 out of 32 , or .16). Although these subjects spontaneously used elaborative processes, which are typically more effective than maintenance processes to remember the study words (see, e.g., Craik \& Watkins, 1973), most of them were not aware of the nature of this experiment and they did not try to determine the critical lures on their own. This was true even after subjects in the cautious group were told that some nonpresented test words would be similar to study words. A far different pattern of results is seen in Table 2 for the subjects in the forewarned group. The most commonly reported strategy for these subjects was to determine the critical lures. Elaborative or maintenance rehearsal was infrequently reported, and the number of subjects who reported no strategy was comparable to the other groups.

The results in Table 2 make two important points. The first point is that the instructions given to the subjects in this task influenced the type of strategy that was used. When subjects were merely told that they would be tested on lists of words (uninformed group) or urged to be cautious for a test (cautious group), the majority of them wisely adopted elaborative rehearsal processes to maximize their memory performance. However, when they were told in advance about the memory illusion (forewarned group), many of these subjects tried to determine the specific critical lures that might appear on the recognition test. The second and more important point is that subjects in all conditions were susceptible to the false recognition effect, regardless of self-reported strategy. If we examine only the categories in Table 2 with the most subjects, the false recognition of critical lures was greater for subjects in the uninformed $(.89)$ and cautious $(.82)$ groups who used elaborative rehearsal than for subjects in the forewarned (.45) group who tried to determine critical lures. But note that even the subjects in the forewarned group who tried to find critical lures falsely recognized nearly half of them. Those subjects understood the forewarning instructions and tried to minimize the false recognition effect, yet they were still influenced by the memory illusion they were actively trying to resist. Clearly, forewarning instructions diminished but did not eliminate the false recognition effect.

\section{An In-Class Demonstration}

As part of a regular meeting of the third author's class (Psychology 221, Human Memory), 25 Wesleyan University students participated in an in-class demonstration on the effect of forewarning. Prior to the demonstration, the students were given a detailed description of Roediger and McDermott's (1995) experiment, along with a sample list and critical lure. The instructor then informed them that they would be read eight lists of words, and their job was to devise a strategy to minimize the false recognition of critical lures. The study lists and recognition test were constructed in the same fashion as in the present experiment. The lists were read at a rate of approximately $1.5 \mathrm{sec}$ per word, and remember and know judgments were not made at test. The results closely paralleled those from the forewarned group in the present experiment for hit rate (.67), false alarms for critical lures (.49), and false alarms for nonstudied words (.19) and unrelated critical lures (.22). Even though the memory students still falsely recognized critical lures more than unrelated critical lures $[t(24)=7.57, S E M=.04, p<$ $.001]$, their level of false recognition for critical lures was lower than their hit rate for studied words $[t(24)=3.40$, $S E M=.05, p<.01]$. These findings indicate that the memory students were susceptible to this memory illusion, albeit at an attenuated level. Thus, in both a formal laboratory setting and a less formal classroom setting, forewarning instructions served to diminish but not eliminate the effect of this memory illusion.

\section{DISCUSSION}

The study demonstrated several important points. First, when subjects were uninformed about the memory illusion, they demonstrated a strong false recognition effect. These subjects falsely recognized critical lures at a rate that was comparable to their hit rate for studied words, and they were more likely to indicate that they specifically remembered those words from study than they were to indicate that they simply knew that they were presented. Second, when subjects were urged to be cautious about false alarms to all words, they still demonstrated a strong false recognition effect, as their false alarm rate for critical lures was comparable to their hit rate for studied words. However, instructions to be cautious decreased the likelihood that falsely recognized critical lures would be remembered from study. Third, when subjects were forewarned about the memory illusion, they demonstrated a diminished false recognition effect. These subjects reduced their false alarm rates for critical lures, and they made remember and know judgments equally often for recognized studied words and critical lures. Fourth, a postexperiment questionnaire indicated that the majority of the subjects in the uninformed and cautious groups used elaborative rehearsal to try to remember the study words, whereas many subjects in the forewarned group tried to determine the critical lures. The subjects in the forewarned group who sought the critical lures were still susceptible to the memory illusion. Finally, the effects of forewarning on false recognition were shown to be reliable by the results of an in-class demonstration.

Our finding that forewarning instructions diminished but did not eliminate the false recognition effect provides an empirical link between perceptual and memory illusions. Roediger and McDermott 
(1995) suggested that the false memory effect functions as a perceptual illusion when they stated that "just as perceptual illusions can be compelling even when people are aware of the factors giving rise to the illusion, we suspect that the same is true in our case of remembering events that never happened" (p. 812). Our results do not disagree; both knowledgeable and uninformed subjects falsely recognized critical lures. The present procedures allowed forewarned subjects the opportunity to devise strategies to reduce their susceptibility to critical lures. Yet even though many subjects in this group sought to determine those critical lures, they still falsely recognized almost half of them. This memory illusion can be influenced by a subject's knowledge because the procedures used in this task allow time for that knowledge to be used. But even when the subjects were armed with this knowledge, false recognitions still occurred. Given the extensive training procedures used in the forewarned condition, it is not obvious how we might have better informed our subjects about this illusion, nor is it clear that a better strategy exists to ward off its effect than trying to determine the critical lures. This strategy was not wholly effective, and its effectiveness would be expected to diminish as the number of study lists grows larger than the memory span. Clearly, even knowledgeable subjects make memory errors in this task.

To explain this memory illusion, some researchers have adopted Underwood's (1965) implicit activation response hypothesis, which suggests that when subjects encode words, they think of semantic associates to those words at study (e.g., Roediger \& McDermott, 1995; Schacter et al., 1996). In the present experiment, listening to lists of semantically related words may have activated representations for critical lures because they are the highest semantic associates of the list items. On the subsequent recognition test, subjects may have falsely recognized those words on the basis of implicit stimulus familiarity or explicit retrieval of the study context. If the representations for the critical lures were not consciously activated at study, subjects may have falsely recognized those words at test, but they may have been more apt to say that they knew that those items were presented than to say that they specifically remembered their presentation. If those representations were consciously activated at study, subjects not only may have falsely recognized those items, but they may also have said that they remembered their presentation. In both instances, subjects would be making a source-monitoring error about the critical lures. Forewarned subjects in the present experiment may have reduced both their false alarm rate and their frequency of remember judgments to critical lures by rejecting any lures at test that were consciously activated at study and identified as related but nonstudied words. However, these subjects would still be prone to false recognitions, albeit at a lower rate and with a lower frequency of remember judgments than the other conditions, because they could still be fooled by critical lures that were nonconsciously activated at study or were consciously activated but not identified as nonstudied words.

Finally, psychologists have long known that memory errors occur in nonlaboratory settings (e.g.. Bartlett, 1932; Munsterberg, 1908), and there is currently great controversy over the possibility of recovered/false memories of childhood abuse (Loftus, 1993). We do not claim that the present paradigm offers a general method for studying false memory or that the present findings can generalize to memories of child abuse (see Freyd \& Gleaves, 1996, and Roediger \& McDermott, 1996, for comments on these issues). Rather, we think that the present false recognition research has practical value in understanding the degree to which knowledge can be used to inoculate a person against a false memory effect. Are memory errors always likely to plague us because remembering is fundamentally constructive in nature, as Roediger and McDermott (1995) have asserted? Or might we overcome these errors by understanding the conditions under which they are likely to occur? Our findings suggest that inoculation by knowledge may achieve only limited success because knowledgeable people can only partially control their susceptibility to remembering events that never occurred.

\section{REFERENCES}

Bartlett, F. C. (1932). Remembering: A study in experimental and social psychology. Cambridge: Cambridge University Press.

Craik, F. I. M., \& Watkins, M. J. (1973). The role of rehearsal in short-term memory. Journal of Verbal Learning \& Verbal Behavior, $12,599-607$

DEESE, J. (1959). On the prediction of occurrence of particular verbal intrusions in immediate recall. Journal of Experimental Psychology, 58, 17-22.

Freyd, J. J., \& Gleaves, D. H. (1996). "Remembering" words not presented in lists: Relevance to the current recovered/false memory controversy. Journal of Experimental Psychology: Learning, Memory, \& Cognition, 22, 811-813.

GREGORY, R. L. (1987). lllusions. In R. L. Gregory (Ed.), The Oxford companion to the mind (pp. 337-347). New York: Oxford University Press.

LofTus, E. F. (1993). The reality of repressed memories. American Psychologist, 48, 518-537.

MCDERmotT, K. B. (1996). The persistence of false memories in list recall. Journal of Memory \& Language, 35, 212-230.

Munsterberg, H. (1908). On the witness stand: Essays on psychology and crime. New York: Doubleday.

Payne, D. G., Elie, C. J., Blackwell, J. M., \& Neuschatz, J. S. (1996). Memory illusions: Recalling, recognizing, and recollecting events that never occurred. Journal of Memory \& Language, 35, 261-285.

RaJARAM, S. (1993). Remembering and knowing: Two means of access to the personal past. Memory \& Cognition, 21, 89-102.

READ, J. D. (1996). From a passing thought to a false memory in 2 minutes: Confusing real and illusory events. Psychonomic Bulletin \& Review, 3, 105-111.

ROEDIGER, H. L., III (1996). Memory illusions. Journal of Memory \& Language, 35, 76-100.

Roediger, H. L., III, \& McDermott, K. B. (1995). Creating false memories: Remembering words not presented in lists. Journal of Experimental Psychology: Learning, Memory, \& Cognition, 21, 803-814.

Roediger, H. L., III, \& MCDermott, K. B. (1996). False perceptions of false memories. Journal of Experimental Psychology: Learning, Memory, \& Cognition, 22, 814-816.

Schacter, D. L., Verfaellie, M., \& Pradere, D. (1996). The neuropsychology of memory illusions: False recall and recognition in amnesic patients. Journal of Memory \& Language, 35, 319-334

Tulving, E. (1985). Memory and consciousness. Canadian Psychologist, 26, 1-12

UNDERWOOD, B. J. (1965). False recognition produced by implicit verbal responses. Journal of Experimental Psychology, 70, 122-129.

(Manuscript received July 17, 1996; revision accepted for publication December 16, 1996.) 